\title{
Of nymphs and nerves
}

I have a message for you. Never tangle with a nymph, especially one of the aquatic variety. If you choose to ignore this advice then on your own head be it, but remember Hans. Now Hans was a character in 'Ondine, a romantic fantasy in three acts' by Jean Giradoux. He was foolish enough to fall in love with Ondine, a water nymph, and when she acted out the romantic fantasy equivalent of a 'Dear John' letter he had this to say, 'Since you left me, Ondine, all the things my body once did for itself, it does now only by special order.... A single moment of inattention and I forget to breathe'. Don't say I didn't warn you.

Talk of nymphs and curses is not best calculated to comfort anxious parents so the disorder which was called Ondine's curse is perhaps better referred to as the primary (or central) alveolar hypoventilation syndrome. The first descriptions were of acquired disease mainly in adults and the congenital syndrome was not described until 1970.' The characteristic finding is hypoventilation due to a low tidal volume with a normal respiratory rate. Hypoventilation occurs only in quiet sleep in milder cases, in quiet and rapid eye movement (REM) sleep in the more severe, and while awake in the most severe. Associated conditions include Hirschsprung's disease, neuroblastoma, ganglioneuroma, and ganglioneuroblastoma. A recent report from Chicago (Debra WeeseMayer and colleagues, fournal of Pediatrics 1992; 120: 381-7) gives details of 32 congenitally affected children.

Fourteen of the 32 patients were girls. There was evidence of birth asphyxia in some patients and all of the children needed mechanical ventilation from an early age. They were first studied by the team in Chicago at ages varying from 1 week to 4 years and 8 months (median 3 months). Physiological studies confirmed hypoventilation with low tidal volumes, normal respiratory rates, hypercapnia, and hypoxaemia worse in non-REM than in REM sleep. Twelve patients showed hypoventilation while awake. The hypoventilation was unresponsive to hypercapnia, hypoxaemia, or both and to pharmacological stimulants.

Ten patients had asthma and two needed a pacemaker for cardiac conduction defects. Although only one patient had pulmonary hypertension when first assessed a further 24 developed it later. Even when they had pneumonia these children had no dyspnoea or tachypnoea. Twenty three had epilepsy. Thirty children had computed tomograms, which showed cerebral atrophy in 12. Five patients had Hirschsprung's disease and 19 were found to have eye problems including esotropia in nine, exotropia in five, ptosis in three, and anisocoria and myopia in one each. One child had multiple ganglioneuroblastomas.

Ten patients died. Of the 22 survivors aged 6 months to 14 years and 8 months, 12 were receiving continuous ventilatory support using diaphragmatic pacing during the day and mechanical ventilation at night. The remaining 10 were coping on their own during the day but at night five had diaphragmatic pacing and five were ventilated. Almost all of the 32 patients were cared for at home and most were able to take part in some age appropriate sports.

A second paper from the same group of workers (Jean Sivestri and colleagues, fournal of Pediatrics 1992; 120: 388-93) gives the results of neuropsychological testing of 17 of the children. Twelve were over 3 years old when tested and their full scale IQ/DQ results ranged from 55 to 115 with only two having a score below 70 . No significant correlations were found between the test results and measures of disease severity. The authors incline to the view that the syndrome is a manifestation of widespread developmental central nervous system pathology but they can not exclude the possibility that some at least, of the pathology may be secondary to hypoxia.

ARCHIVIST

1 Mellins RB, Balfour HH Jr, Turino GM, Winters RW. Failure of automatic control of ventilation (Ondine's curse). Report of an infant born with this syndrome and review of the literature. Medicine 1970; 49: 487-504. 